\title{
Why have consumers opposed, postponed, and rejected innovations during a pandemic? A study of mobile payment innovations
}

\section{Shalini Talwar}

KJ Somaiya Institute of Management Studies and Research, Mumbai, India

\section{Manish Talwar}

Alkesh Dinesh Mody Institute for Financial and Management Studies, Mumbai, India

\section{Puneet Kaur}

Department of Psychosocial Science, University of Bergen, Bergen, Norway

Optentia Research Focus Area, North-West University, Vanderbijlpark, South Africa

\section{Gurmeet Singh}

The University of the South Pacific, Fiji

\section{Amandeep Dhir}

School of Business \& Law, University of Agder, Kristiansand, Norway

Norwegian School of Hotel Management, University of Stavanger, Stavanger, Norway Optentia Research Focus Area, North-West University, Vanderbijlpark, South Africa amandeep.dhir@uia.no

\section{Abstract}

The highly infectious nature of the COVID-19 virus has made the use of contactless payment methods a health exigency. Yet, consumers are resisting using mobile payments (m-payments) during the pandemic, a confounding behavior that needs to be better understood. The present study explicates this behavior by examining consumer resistance to m-payments during the COVID-19 pandemic. In addition, it provides more granular findings by measuring three levels of resistance/non-adoption, namely, postponement, opposition, and rejection. In this way, the study adds depth to the literature, which has largely examined resistance at an aggregate level to yield generic findings. Toward this end, the study draws upon the Innovation Resistance Theory (IRT) to propose that usage, value, risk, tradition, and image barriers influence the three levels of resistance/non-adoption differently. An artificial neural network analysis (ANN) of the data collected from 406 non-users of m-payments confirmed that the influence of the five barriers varies for the three levels of resistance/non-adoption. The results further suggest that the usage barrier is the most significant contributor to opposition and rejection intentions toward m-payments, whereas the image barrier is the most influential for postponement intentions. This study thus makes a useful contribution to theory and practice.

Keywords: Consumer resistance, functional and psychological barriers, innovation resistance theory, non-adoption, mobile wallets

\section{Introduction}

COVID-19 has transcended geographical boundaries with a global pandemic that has an exponentially rising number of confirmed cases and deaths (UNDP, 2020; WHO, 2020a). 
Countries have responded to the pandemic by introducing various control measures, including complete domestic shutdown or lockdown of activity, social distancing norms, travel restrictions, and provisions of quarantine for those who have been exposed to the virus (Fang, Nie, \& Penny, 2020). The transmission routes of COVID-19 span not only the spread through infected individuals but also through contaminated surfaces (WHO, 2020b). Therefore, the risk of infection through physical currency, such as banknotes and coins, cannot be ignored, given that the virus can survive on solid surfaces for several days (Doremalen et al., 2020). In fact, research during pre-COVID-19 times has revealed that human influenza viruses deposited on currency notes could survive and remain infectious for extended periods (Thomas et al., 2008). Other studies have also confirmed that currency notes can be contaminated with a variety of pathogenic bacteria that transmit infections to the individuals who handle them (Abd Alfadil, Mohamed, Ali, \& El Nima, 2018). Given the extremely infectious nature of COVID-19 virus (Xu et al., 2020), it is pertinent to expect that individuals may worry about its transmission through currency notes, thereby resorting to the use of contactless payment transactions, e.g., mobile wallets (m-wallets). Thus, it can be argued that the pandemic presents an opportunity to divert individuals' habit of using cash towards digital modes of transactions instead, an agenda that governments have been pursuing for quite some time (Jakhiya, Bishnoi, \& Purohit, 2020).

Based on the above discussion, we can say that a silver lining in the gloom of the COVID-19 pandemic is that, globally, there is a hope that the use of digital payments, which include all non-mobile and mobile payments made through the internet, will exponentially increase as people avoid the use of currency notes for fear of the virus transmission. Initial media reports about the increased usage of digital payment modes seem to confirm this expectation. For instance, according to a report in the initial weeks of the pandemic (i.e., March 2020 onward), $42 \%$ of individuals in India used different modes of digital payment solutions (both nonmobile and mobile) more than during the pre-pandemic period (ET Government, 2020). However, a more recent report published in July 2020 suggested that $53 \%$ of individuals in India have reported no change in their use of digital payment methods during the postpandemic lockdown period, with only $9 \%$ reporting the exclusive use of them (Jaganmohan, 2020). These reports have highlighted that the use of digital payment methods may not have increased as much as anticipated during the pandemic. A more worrying thought is whether the reported increase in the usage of digital payment solutions is only temporary and, if so, whether individuals will return to their pre-pandemic transaction behavior, i.e., revert to using currency notes for transactions, after the pandemic ends. This is an important manifestation that service providers facilitating various digital modes of payments, as well as governments and policymakers, want to understand.

A comprehensive review of the extant literature has revealed that even before the onset of the COVID-19 pandemic, the diffusion of digital payment systems, particularly m-payments, was a global concern in both advanced and emerging economies, despite the ease of interface they offer through smartphones. For example, even in an advanced economy such as Japan, 73\% consumers had used currency notes for daily transactions in 2019 (Fujiki, 2020). In fact, with the exception of China, where the use of m-payments reached 86\% in 2019 (Yin, Gong, Guo, \& $\mathrm{Wu}, 2019)$, other countries have continued to see a lower utilization rate. The low diffusion or non-adoption of m-payment usage has attracted the attention of researchers, who have noted the existence of certain barriers that cause individuals to resist the use of m-payments (e.g., 
Kaur, Dhir, Singh, Sahu, \& Almotairi, 2020a; Leong, Hew, Ooi, \& Wei, 2020; Laukkanen, 2016; Gupta \& Arora, 2017), despite the benefits they offer. In this regard, a recent study also examined the existence of barriers toward the use of m-payments for booking travel during the COVID-19 pandemic (Khanra, Dhir, Kaur, \& Joseph, 2021). However, the previous literature providing a resistance perspective is limited, with most of the past studies on mpayments offering adoption-related findings (e.g., Chatterjee \& Bolar, 2019; Kaur, Dhir, Bodhi, Singh, \& Almotairi, 2020b; Talwar, Dhir, Khalil, Mohan, \& Islam, 2020c; Gao \& Waechter, 2017; Silic \& Ruf, 2018). Indeed, consumer resistance to digital innovations, in general, continues to be less examined than consumer adoption behavior toward such innovations (Talwar et al., 2020a).

Underscoring the importance of the resistance perspective, Ram and Sheth (1989) proposed the framework of Innovation Resistance Theory (IRT), which explained the resistant behavior of consumers through five barriers: namely, usage, value, risk, tradition, and image. IRT uses these barriers to explain the functional and psychological factors that cause consumers to resist a given innovation. Extending the resistance debate further, scholars have equated resistance with non-adoption, and proposed its three levels, namely, postponement, opposition, and rejection (e.g., Kleijnen, Lee, \& Wetzels, 2009; Szmigin \& Foxall, 1998). Such disaggregation of resistance offers deeper insights into the process of consumer decision-making when resisting the adoption of innovations.

Despite the seminal work to support an understanding of consumers' resistance/non-adoption behavior toward the products and services offered to them, consumer resistance continues to be an under-explored phenomenon at the aggregate level. Even fewer studies have examined the antecedents of resistance or non-adoption by disaggregating them into the three levels of postponement, opposition, and rejection, despite scholars' initial interest in examining resistance to mobile and internet banking (Elbadrawy \& Abdel Aziz, 2011; Laukkanen, 2016; Laukkanen, Sinkkonen, \& Laukkanen, 2008). Recent studies have also noted the lack of empirical evidence to explicate how different barriers affect the three levels of resistance behaviors (Chen, Lu, Gong, \& Tang, 2019; Talwar et al., 2020a). Such a lack of findings, especially in the context of m-payment non-adoption, represents a research gap that needs to be addressed, particularly as scholars have found that the enablers of adoption are not very useful in explaining resistance or non-adoption behavior (Claudy, Garcia, \& O'Driscoll, 2015; Talwar, Dhir, Kaur, \& Mäntymäki, 2020b).

We argue that the ongoing pandemic offers an opportunity to examine the resistant consumer behavior toward digital payment methods, in general, and m-payments, in particular, despite the contingent need to use them as an infection avoidance approach. Specifically, we posit that the academic research on consumer resistance to m-payments, especially in the context of a pandemic, needs to be deepened in terms of (a) further examination of barriers toward the use of m-payments for transactions, (b) the varying levels of consumer resistance to m-payments, i.e., postponement, opposition, and rejection behaviors, and (c) the resistant behavior of consumers toward m-payments despite the safety benefits they offer in the current pandemic period. Responding to this need, we utilized the theoretical framework of IRT to examine consumer resistance to m-payments during the pandemic through the following research questions: 
RQ1: Do usage, value, risk, tradition, and image barriers toward the use of mobile payments (m-payments) during the pandemic impact varying levels of resistance/non-adoption, i.e., postponement, opposition, and rejection?

RQ2: Is there a difference between the relative influence of usage, value, risk, tradition, and image barriers toward the use of m-payments during the pandemic on the varying levels of resistance/non-adoption, i.e., postponement, opposition, and rejection?

To test the developed research model, we collected data from 406 non-users of m-wallets (e.g., a form of m-payments) during the present pandemic. We then analyzed the collected data using the artificial neural network (ANN) method to uncover the influential barriers and yield robust results, taking both the linear and non-linear relationships of the proposed antecedents with the identified outcome variables.

The novelty of the study comes from the following: (a) it is the first empirical study to examine postponement, opposition, and rejection toward m-wallets, which are a very versatile form of $\mathrm{m}$-payments that have remained under-explored from the resistance perspective; (b) it is one of the limited studies to use ANN, rather than structural equation modeling, as the methodological approach to analyze consumer resistance to m-payments; and (c) the study has been conducted during the ongoing COVID-19 pandemic, thereby providing insights into the payment behavior of consumers during a global health crisis. This area has remained under-researched so far.

The rest of the study is structured as follows: we discuss the theoretical background and research model in Sections Two and Three, present the data and methods in Section Four, followed by the results in Section Five, the discussion in Section Six, and the conclusion, implications, limitations, and future research areas in Section Seven.

\section{Theoretical background}

\subsection{Innovation resistance theory (IRT)}

Innovation resistance as a concept is relatively new compared with the adoption perspective. Ram (1987) was the first to discuss the idea that resistance was not the opposite of adoption. Other scholars have supported this claim, arguing that not only is innovation resistance an independent attitude, but that resistance can also co-exist with adoption (e.g., Oh, Park, \& Min, 2019). IRT (Ram \& Sheth, 1989) presents a formal attempt at providing a theoretical framework to capture the sources of resistance that may cause consumers to avoid adopting an innovation. The theory postulates that consumers resist innovations that present potential alternation in the status quo or are misaligned with their beliefs or values. IRT proposes two broad classes of barriers, namely, functional, and psychological, as measures of consumer resistance toward innovations. These barriers translate into resistance, thereby implying that the consumers do not accept the innovation. This non-acceptance is, in essence, non-adoption, as discussed in the next section.

The three classic functional barriers correspond with usage, value, and risk. Usage barriers are related to using the innovation and the adjustments that the consumers need to make to do so based on the complexity or lack of compatibility of the innovation; value barriers, meanwhile, are related to the benefit an innovation gives over its substitutes, as seen from a performanceto-price perspective; and, finally, risk barriers represent the perceived threats, such as 
breaches of privacy and financial risk, that are associated with adopting the innovation (Laukkanen, Sinkkonen, Kivijärvi, \& Laukkanen, 2007; Talwar et al., 2020a).

The two classic IRT psychological barriers correspond with tradition and image. Tradition barriers are related to the consumers' perception of how the offered innovation deviates from the norms of society, thereby requiring them to act against well-entrenched traditions; image barriers, meanwhile, are related to the extent to which the innovation has an unfavorable image in the eyes of the consumer (Claudy et al., 2015). Although subsequent to the introduction of IRT, other barriers have been proposed and examined, such as the vulnerability barrier (e.g., Talwar et al., 2020b; Talke \& Heidenreich, 2014). However, we consider only the five generic IRT barriers in our study since these appreciably capture the breadth of consumers' resistance to innovation.

IRT provides a suitable theoretical lens for our study for the following reasons: (a) we propose to examine different levels of resistance in non-users of m-payments, and IRT barriers are welldocumented in the research as antecedents of consumer resistance in the context of mobile banking and other related financial services (e.g., Kaur et al., 2020a; Leong et al. 2020; Laukkanen, 2016); (b) IRT allows us to understand resistance to innovation as a combination of both attitude and behavior (e.g. Bagozzi \& Lee, 1999), which helps us better explicate varying levels of resistance; (c) Scholars have proposed IRT and its extended versions as a useful basis for explaining pre-adoption behavior in the area of finance ( e.g., Seth, Talwar, Bhatia, Saxena, \& Dhir, 2020); and (d) IRT has been invoked by scholars to examine the nonadoption of digital innovation, yielding robust results and offering deeper insights into the slow or no diffusion of innovations in the digital domain (e.g., Soh et al., 2020).

\subsection{Non-adoption versus resistance toward innovations}

Over time, researchers realized that the enablers of innovation adoption were not very effective in explaining the inhibiting factors that could lead to non-adoption and resistance (e.g., Kleijnen et al., 2009; Szmigin \& Foxall, 1998). Non-adoption of innovation, as discussed above, is actually the non-acceptance of innovation, which manifests as consumer resistance. There are two streams of thought in the existing literature. The first considers non-adoption and resistance as synonyms and describes them accordingly (e.g., Claudy, O'Driscoll, Garcia, \& Mullen, 2010). The second stream considers resistance to be a subset of non-adoption (e.g., Patsiotis, Hughes, \& Webber, 2013). In the following discussion, we outline the contours of both streams to present a complete picture of the thought process that has evolved over the past few decades in the context of resistance and non-adoption.

\subsubsection{Non-adoption and resistance as identical concepts}

One of the earliest mentions of non-adoption of innovation was in 1976 by Mittelstaedt, Grossbart, Curtis, and Devere (1976). They identified three key factors as the causes of this non-adoption. First is symbolical rejection, wherein consumers use the information available to decide that the product is not suitable for them; second is that although consumers accept the innovation symbolically, other factors make them unwilling to adopt the innovation; and the third is that although consumers symbolically adopt the innovation and are also willing to accept it, they still postpone the adoption. Thus, non-adoption may manifest as one of the three responses of consumers, namely, postponement, opposition, and rejection. 
Later, a shift in the focus from the non-adoption of innovation to the resistance toward it occurred (Szmigin \& Foxall 1998), wherein scholars used postponement, opposition, and rejection as three levels of resistance to explain the resistant behaviors of consumers. For instance, Claudy et al. (2010) discussed resistance as a consumer response spanning its weak form (postponement) to strong form (rejection), arguing that the factors causing resistance were varied and possibly related to social context, the features of the innovation, and the complex interaction of retail consumers with one another. From this perspective, non-adoption and consumer resistance may be seen as similar concepts. The three terms are described in detail below.

Postponement is a milder form of non-adoption or resistance that refers to a delay in the decision to adopt by actively deciding to defer adoption for the time being (Cornescu \& Adam, 2013; Kuisma, Laukkanen, \& Hiltunen, 2007). It represents a situation in which consumers prefer to wait despite finding the innovation acceptable (Gatignon \& Robertson, 1989). Furthermore, postponement is largely attributable to situational factors (Poon, 2008). Interestingly, Nabih, Bloem, and Poiesz (1997) argued that postponement offers an escape route for consumers when faced with the dilemma of adopting the innovation or not. A similar view was posited by Gurtner (2014), who argued that postponement is a temporary manifestation that is associated with a passive denial to immediately accept or reject the innovation.

Opposition represents an active attack or protest directed toward an innovation (Kuisma et al., 2007; Kleijnen et al., 2009). Scholars have argued that while opposition is a form of rejection, it is not an outright one since consumers may be willing to evaluate the innovation further or collect more information about it before actually rejecting it (Cornescu \& Adam, 2013; Hosseini et al., 2016). Presenting a more aggressive picture of opposition, Gurtner (2014) defined it as overt behavior with an objective to prevent others from accepting an innovation. Notably, opposition is a much stronger response than postponement and is attributable to factors, such as habits, situations, a perceived disadvantage, or cognitive style (Kleijnen et al., 2009; Poon, 2008).

Rejection is the strongest form of non-adoption. It is usually seen in the case of innovations that consumers feel have nothing worthwhile to offer, causing a straightforward refusal to accept them (Patsiotis et al., 2013; Talwar et al., 2020a). Thus, rejection implies the outright, direct, and active non-adoption of an innovative offering (Cornescu \& Adam, 2013; Kleijnen et al. 2009; Lian \& Yen, 2013). The possible reasons behind rejection could be the complexity, riskiness, or lack of value offered by the innovation (Szmigin \& Foxall, 1998), or else the consumer's perception that it is not appropriate for them, based on the existing information (Szmigin \& Foxall, 1998). Rejection may also occur due to inertia on the part of consumers (Ganiere, Chern, Hahn, \& Chiang, 2004), their conservatism (Hirschheim \& Newman, 1988), or their tendency to adhere to the status quo (Woodside \& Biemans, 2005). Furthermore, rejection can be passive or active, with passive rejection being a situation where the innovation is not even considered, and active rejection implying a situation where it is considered but ultimately rejected (Pousttchi \& Schurig, 2004).

Adding one more perspective, Kuisma et al. (2007) argued that opposition could transform into rejection or adoption over time. Similarly, Cornescu and Adam (2013) posited that postponement could also turn into adoption or rejection eventually. 


\subsubsection{Resistance as a subset of non-adoption}

Presenting a different view from the one discussed above, Chen et al. (2019) distinguished between non-adoption and resistance. In this context, non-adopters may be seen as consumers who do not adopt an innovation offered in the market (Dickerson \& Gentry, 1983), and resistors may be seen as postponers who may be delaying the decision until a more suitable time (Laukkanen et al., 2008). In addition, resistors could also be opponents with a negative attitude toward the offered innovation (Kleijnen et al., 2009) or rejecters who have made a decision not to adopt the innovation (Laukkanen et al., 2008). Patsiotis et al. (2013) also endorsed the view that non-adoption is different from resistance, arguing that while the nonadoption of an innovation may be attributable to a high degree of resistance, there are other factors that may lead to this outcome. Such factors could include a lack of need, low awareness, or inertia (Suzuki \&Williams, 1998; Patsiotis et al., 2013). In fact, resistance may be best looked at as a subset of non-adoption (Patsiotis et al., 2013).

\subsubsection{Mapping non-adoption and resistance to the present context}

The preceding discussion provides the basis for considering non-adoption and resistance as identical concepts, which manifest toward m-payments in three levels, namely postponement, opposition, and rejection. In consonance with Kleijnen et al. (2009), we interpret postponement as the decision of the consumers to wait to adopt any innovation, opposition as the aggressive objection of it, and rejection as the outright refusal to accept it based on their cognitive evaluation of it. Drawing on the study by Mohtar and Abbas (2015), we further consider postponement, opposition, and rejection as three forms of active resistance. To better explicate the three levels, we use the five classic IRT barriers as antecedents of these manifestations toward m-payment usage during the pandemic.

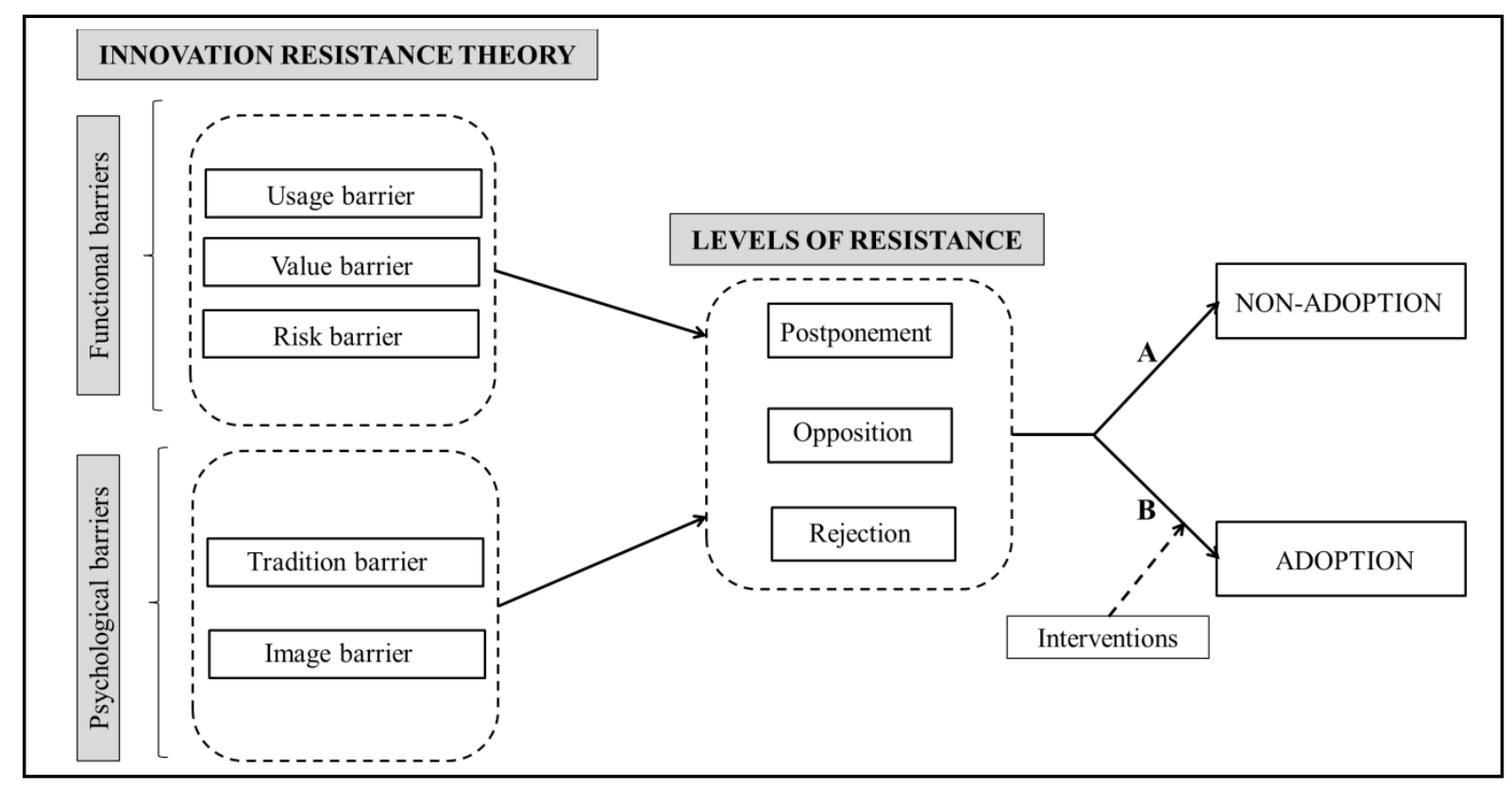

Figure 1. Non-adoption versus adoption (NAA) framework

Since the research on the influence of barriers on the three levels of resistance/non-adoption is still in its nascent stages, we propose a transition framework, titled the Non-adoption versus Adoption (NAA) framework, presented in Figure 1, to provide conceptual clarity about the dynamics of the barriers and the levels of resistance/non-adoption and adoption. The 
framework represents the essence of the preceding discussion and posits two outcomes. Outcome A indicates the non-acceptance of innovation in the absence of any interventions to engage with potential resistors. It implies that the five IRT barriers may lead to three levels of resistance, which are actually manifestations of non-adoption (e.g., Mittelstaedt et al., 1976; Szmigin \& Foxall, 1998; Claudy et al., 2010). However, there is also a possibility that nonadoption, particularly postponement and opposition, may transform into adoption, as argued by past studies (i.e., Kuisma et al., 2007; Cornescu \& Adam, 2013). This possibility is captured in Outcome B, wherein we posit that the interventions introduced by service providers can cause the postponers, opposers, and rejectors to change their minds and adopt the innovation.

\section{Research model}

As illustrated in Figure 2, we examine the relative influence of IRT barriers (i.e., usage, value, risk, tradition, and image) on three levels of resistance/non-adoption (i.e., postponement, opposition, and rejection) in the context of m-payment use during the pandemic. The review of the extended literature revealed that scholars have organized similar investigations in different contexts, such as online shopping (Lian \& Yen, 2013), mobile health applications (Gurtner, 2014), mobile banking (Laukkanen, 2016), brand mobile apps (Chen et al., 2019) and convergence products (Park \& Koh, 2017).

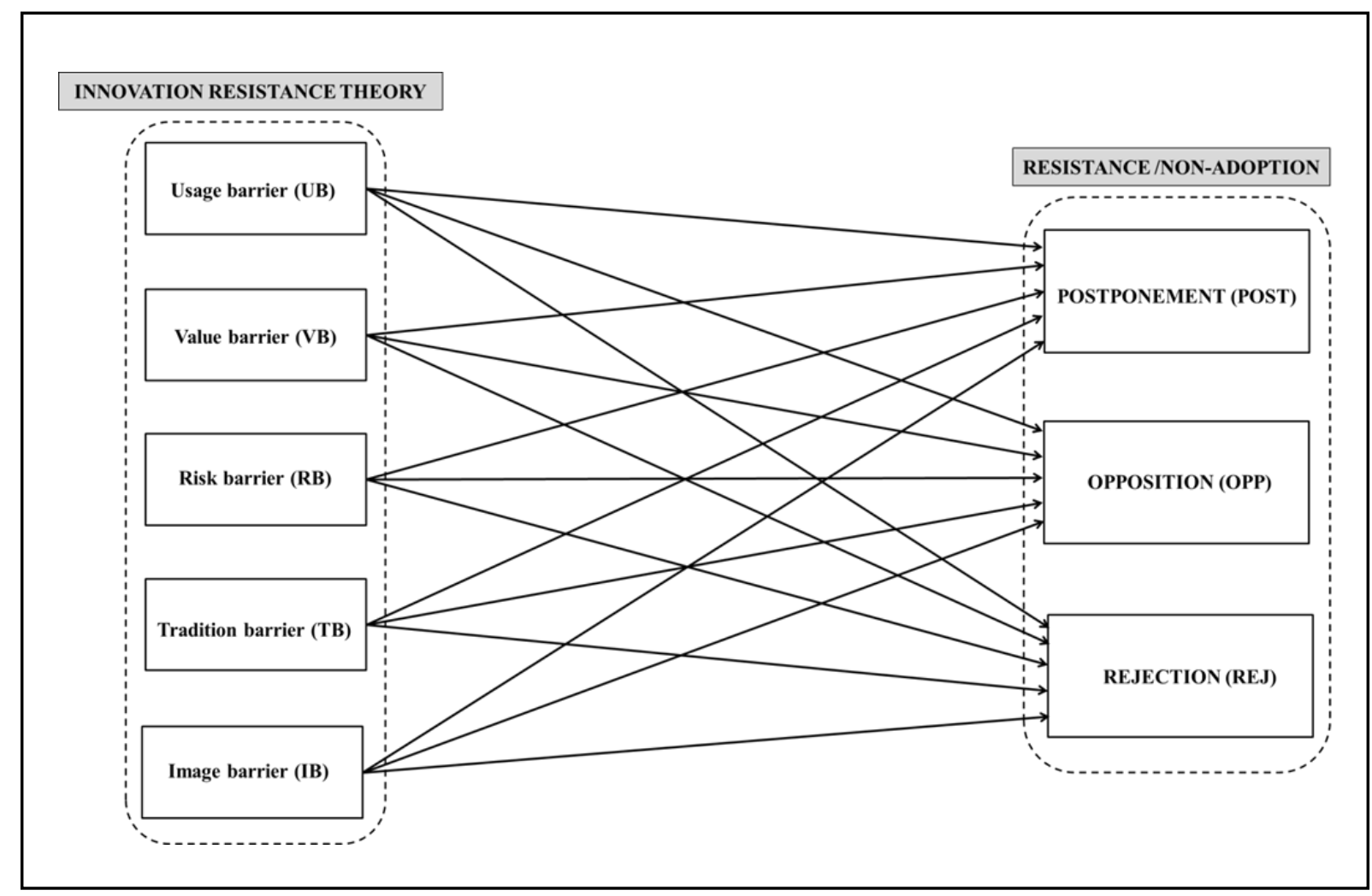

Figure 2. Research model

Chen et al. (2019) revealed differences in the effect of three IRT barriers, i.e., usage, image, and value, on the three levels of resistance toward brand mobile apps. Specifically, usage and image barriers significantly affected rejection, while value barriers significantly affected postponement and opposition. Park and Koh (2017) similarly identified differences in the antecedents of rejection and postponement, finding that rejection was associated with the 
expectation of higher quality coupled with lower price, while postponement was associated with the expectation of lower price. The study also found that the perceived pace of technology change indirectly affected rejection and postponement.

In another digital context, Laukkanen et al. (2008) examined the effect of the five IRT barriers on the three non-adopter groups in the context of their usage intentions toward internet banking: postponers, opponents, and rejectors. The outcome of their empirical analysis confirmed significant statistical differences among the three non-adopter groups in terms of the IRT barriers. Specifically, these groups differed in the degree of the usage, value, tradition, and image barriers they had toward Internet banking. Furthermore, the study revealed that the differences were highest for usage barriers followed by those for image, value, and tradition. Moreover, the three groups did not differ in terms of risk barrier as the risk perception for internet banking was high across all three categories. Elbadrawy and Aziz (2011) similarly classified the non-adopters of mobile banking into postponers, opponents, and rejectors. Their study examined the effect of the five IRT barriers on these non-adopters, revealing that the three groups differed significantly with regard to usage, value, and image barriers. In comparison, no statistically significant differences were found between the groups regarding the risk and tradition barriers. Consolidating these findings, Laukkanen (2016) examined adopters versus non-adopters in the context of mobile banking and internet banking. The results showed that the value barrier was the most statistically significant barrier toward the adoption of both banking methods. Moreover, the image barrier was found to slow down the adoption of mobile banking, while the tradition barrier led to the rejection of internet banking.

A limited number of studies have examined the three levels of resistance or non-adoption in other digital contexts. For instance, Gurtner (2014) examined the usage, value, risk, and tradition barriers as antecedents of rejection and opposition toward mobile health applications. The study measured the risk barrier through physical, performance, and social risk and found differences in the effect of these barriers on rejection and opposition. Whereas rejection was significantly predicted by usage, value, and performance risk barriers, opposition was predicted by physical and performance risk instead. Similarly, Lian and Yen (2013) used IRT to examine resistance to online shopping in the context of a cosmetic company. The empirical findings indicated that value and tradition barriers toward usage intentions were the major cause of resistance. The results also revealed that the non-adopter groups differed in terms of usage and image barriers, such that rejectors were found to have the highest barriers, followed by opponents and postponers. In sum, significant differences in usage, value, tradition, and image barriers were found between adopters and non-adopters in the context of online purchase of experience goods.

The above discussion confirms that examining non-adoption by breaking it down into three levels is quite informative and can help theorists and managers develop more effective strategies to counter resistance in the form of IRT barriers. Given that non-adoption can impede the diffusion of innovations (Talwar et al., 2020a), we contend that the academic research related to the three levels of resistance/non-adoption is limited not only in terms of the depth of findings but also in terms of the variety of digital innovations examined. Due to this, we expect that examining the three levels of resistance/non-adoption in the context of mpayments during the pandemic will further enrich the accumulated knowledge along with providing useful insights for researchers and service providers in the area. Thus, we propose 
to examine the effect of five classic IRT barriers on the three levels of resistance/non-adoption to uncover their differential influence.

\section{Data and methods}

The online data collection method is quite popular in the consumer behavior literature (e.g., Sharma et al., 2020a; Sharma, Singh, \& Pratt, 2020b). As such, we collected the data for the study through an online survey conducted in India during August 2020. The survey link was shared on different social media platforms, including Facebook and WhatsApp. We followed a robust process to prepare the survey questionnaire. First, informal interviews were conducted with seven participants representing the target user group of non-users of $\mathrm{m}$ payments and three experts (two professors and one market researcher). The purpose of these interviews was to evaluate the content and face validity of the preliminary questionnaire, which had been prepared by adapting pre-validated, multi-item scales, to assess the relevance, semantics, and clarity of each item included.

\begin{tabular}{|c|c|c|}
\hline Profile & Frequency & $\%$ \\
\hline \multicolumn{3}{|l|}{ Gender } \\
\hline Female & 161 & 39.66 \\
\hline Male & 245 & 60.34 \\
\hline \multicolumn{3}{|l|}{ Age group } \\
\hline 25 years and below & 74 & 18.23 \\
\hline 26-35 years & 113 & 27.83 \\
\hline $36-45$ years & 105 & 25.86 \\
\hline $46-55$ years & 95 & 23.40 \\
\hline 56 and above & 19 & 4.68 \\
\hline \multicolumn{3}{|l|}{ Monthly income (INR) } \\
\hline 25000 or less & 16 & 3.94 \\
\hline 25001- 50000 & 116 & 28.57 \\
\hline $50001-75000$ & 172 & 42.36 \\
\hline 75001-100000 & 57 & 14.04 \\
\hline more than 100000 & 45 & 11.08 \\
\hline \multicolumn{3}{|l|}{ Educational background } \\
\hline Pursuing/completed graduate degree & 169 & 41.63 \\
\hline Pursuing/completed a post-graduate degree & 208 & 51.23 \\
\hline Pursuing/completed doctorate (PhD or equivalent) & 29 & 7.14 \\
\hline \multicolumn{3}{|l|}{ Household size } \\
\hline Single & 54 & 13.30 \\
\hline Married but no children & 93 & 22.91 \\
\hline Married and one child & 221 & 54.43 \\
\hline Married and more than one child & 38 & 9.36 \\
\hline
\end{tabular}

Table 1. Socio-demographic profile of respondents

We used the input from the interviews to modify the items and prepare the final survey instrument. All items were measured on a 5-point scale varying from ' 1 ' = strongly disagree 
and ' 5 ' = strongly agree. All five barriers were measured through a 5-item scale, with the exception of the value barrier, which was measured through a 4-item scale adapted from Kaur et al. (2020a), Laukkanen (2016), and Talwar et al. (2020b). The three levels of resistance/nonadoption were measured through a 5-item scale for postponement and opposition and a 4item scale for rejection, which was adapted from Chen et al. (2019) and Park and Koh (2017). The first page of the online survey clarified the study objectives, the preservation of anonymity, and the absence of an incentive for responding to the survey questions.

We recruited respondents using three screening criteria: (a) they should be non-users of $\mathrm{m}$ wallets (representing m-payments) before and during the COVID-19 pandemic, (b) they should possess a smartphone and have experience using mobile apps, and (c) they should be aware of different m-payment methods. India was selected as the geography of interest since scholars have noted that despite the recent push by the Indian government to promote $\mathrm{m}$ payment use (Jakhiya, Bishnoi, \& Purohit, 2020), the usage of such methods, particularly mwallets, has not increased much (Talwar, Talwar, Najmul Islam, \& Dhir, 2020e). For instance, only $6 \%$ of Indians use m-wallets compared with $36 \%$ of users in China (Bepari, 2019). Resistance toward m-payments has continued to manifest even during the pandemic (Khanra et al., 2021), despite the health benefit of using contactless payment methods. Given that India has a large number of smartphone users and significantly improved internet connectivity, the reasons for non-adoption of m-payments go beyond infrastructural issues. There is thus a need to understand this phenomenon better to help the regulators and service providers develop and implement strategies to lower such resistance.

We received 450 responses, and the final dataset of 406 was taken forward for further analysis after removing 44 invalid responses. Table 1 presents the socio-demographic profile of the respondents in terms of their age, gender, monthly income, educational background, and household size.

We analyzed the data using the ANN method since it was the most suitable approach, given the sample size and multivariate characteristics of the data collected. ANN is a novel approach that yields robust results, yet it is less utilized as compared to covariance-based structural equation modeling (CB-SEM), which is more commonly used (Talwar, Dhir, Kaur, Zafar, \& Alrasheedy, 2019; Kumar, Dhir, Talwar, Chakraborty, \& Kaur, 2021).

\section{Results}

\subsection{Data characteristics}

We assessed the four multivariate assumptions of normality, homoscedasticity, linearity, and multicollinearity to better understand the nature of the data under study. First, we conducted the Kolmogorov-Smirnov (K-S) test to check the distribution of the data, per the recommendation of scholars (e.g., Simard \& L'Ecuyer, 2011). The results revealed that the data followed a non-normal distribution. Since CB-SEM requires the data to be normally distributed, ANN was more suited for analysis in the present study. Although ANN has no homoscedasticity or heteroscedasticity restrictions, we also examined the data for homoscedasticity to better understand its nature. Of the three dependent variables, the data for rejection appeared to be homoscedastic, while it was heteroscedastic for postponement and opposition. This was visually confirmed by the scatter plot of the residuals and three dependent variables (Figures 3-5). 
In consonance with recent studies (Talwar, Talwar, Kaur, \& Dhir, 2020f; Hew, Leong, Tan, Ooi, \& Lee, 2019), we conducted an ANOVA test and found that all three dependent variables (postponement, opposition, and rejection) had a non-linear relationship with the usage, value, and image barriers. Opposition and rejection had a non-linear relationship with the risk barrier as well. Furthermore, all three dependent variables had a linear relationship with the tradition barrier.

Although ANN is suitable for both linear and non-linear relationships, the existence of nonlinear relationships further supported the use of ANN in the present study. Finally, we examined the data for the issue of multicollinearity, as suggested by recent studies (Talwar et al., 2019; Talwar et al., 2020e). For all three dependent variables, the values of tolerance and Variance Inflation Factor (VIF) were within the recommended limits, with tolerance being more than 0.1 and VIF being less than 5 (Hair, Black, Babin, \& Anderson, 2016).

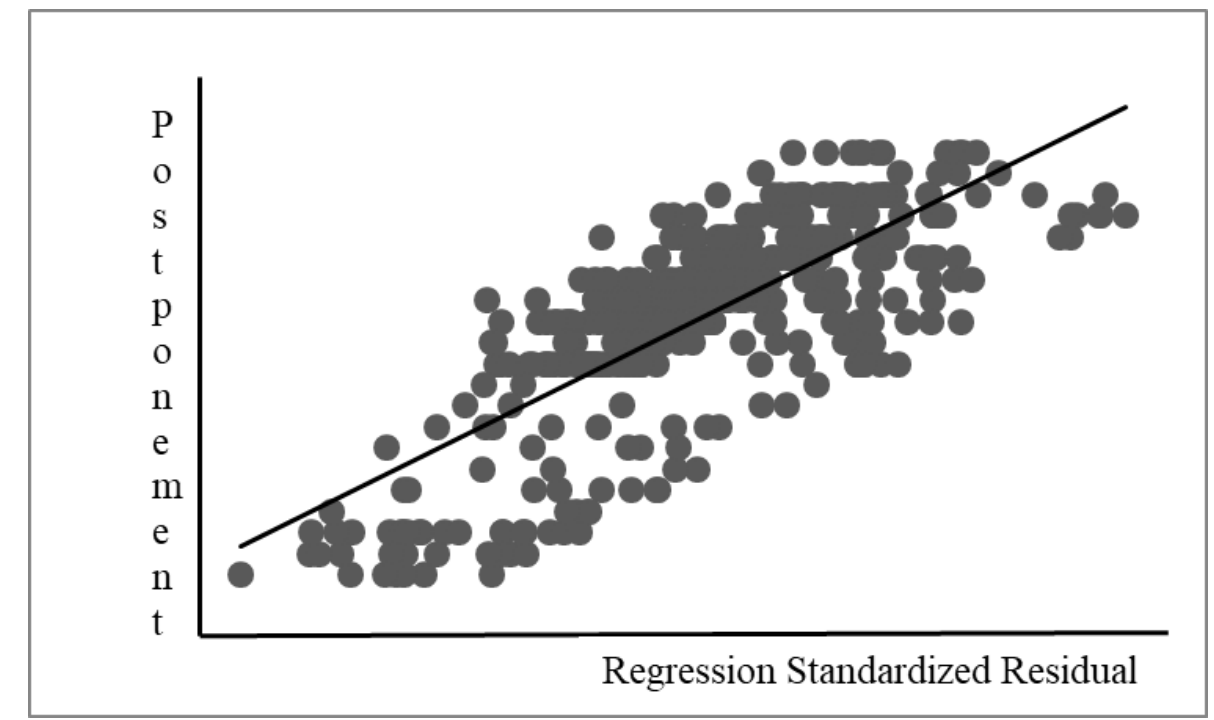

Figure 3. Test of homoscedasticity/heteroscedasticity (Postponement)

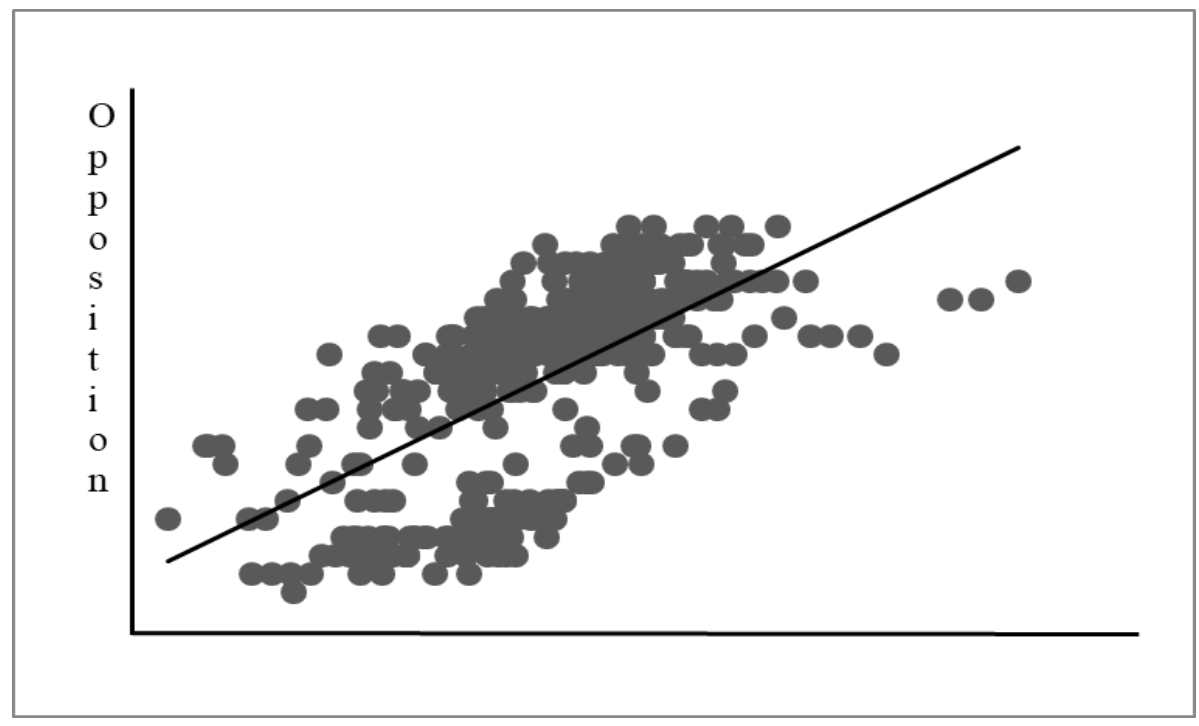

Figure 4. Test of homoscedasticity/heteroscedasticity (Opposition) 


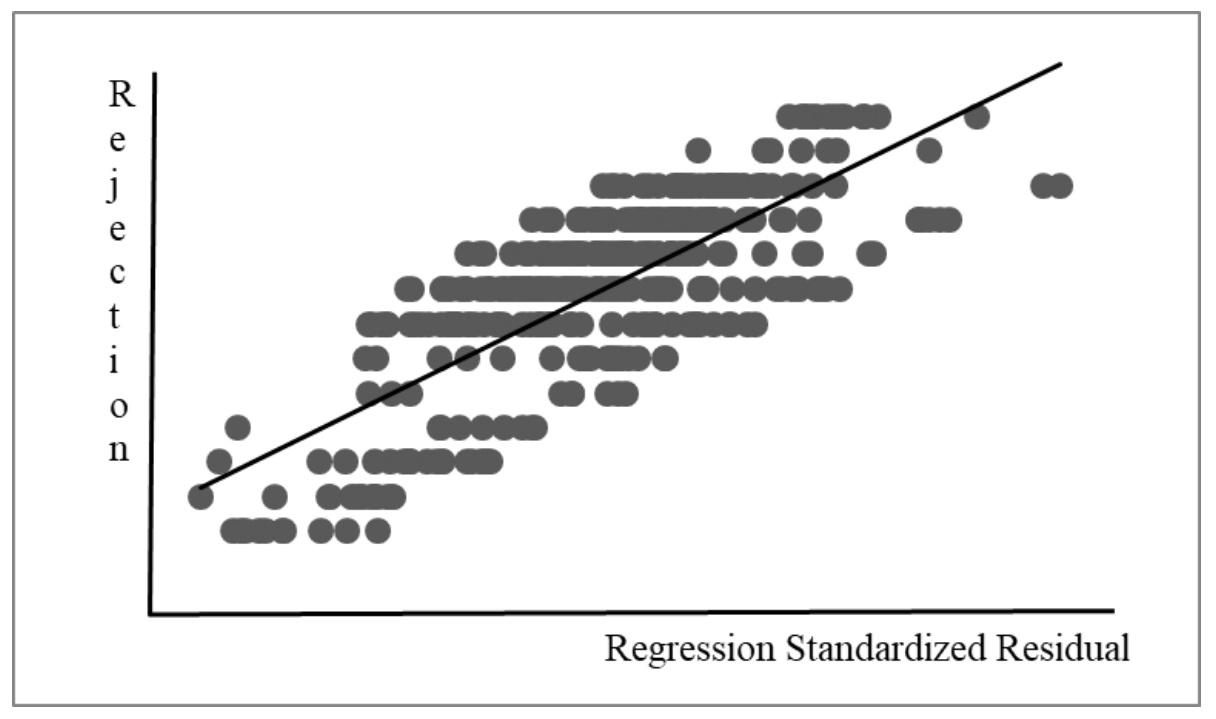

Figure 5. Test of homoscedasticity/heteroscedasticity (Rejection)

\subsection{Common method variance (CMV)}

Since the data was collected using a single survey instrument, it might have the issue of common method variance (CMV), although we followed all procedural remedies at the instrument development and data collection stages. Therefore, we used Harman's single factor test to rule out the possibility of CMV (Podsakoff, MacKenzie, Lee, \& Podsakoff, 2003) and found that a single factor explained only $41.06 \%$ of the total variance explained, which is below the required cut-off of $50 \%$.

\subsection{Validity and reliability of the survey instrument}

To evaluate the validity and reliability of the survey instrument, we conducted a confirmatory factor analysis. First, Cronbach's alpha and the composite reliability (CR) values for all constructs were more than 0.7, confirming the reliability of the survey instrument. Next, the average variance extracted (AVE) value exceeded 0.5 for all constructs, thereby demonstrating their convergent validity. Finally, since the square roots of AVEs were higher than the corresponding correlations, we concluded that the instrument had discriminant validity as well. The inter-construct correlations were also less than 0.8 , as recommended. Thus, all of the validity and reliability measures that we examined conformed to the recommended cut-offs values indicated by prior studies (Hair et al., 2016; Kumar et al., 2021; Talwar, Dhir, Kaur, \& Mäntymäki, 2020d). Table 2 presents the specific values of the validity and reliability measures.

\subsection{Predictive accuracy of the ANN models}

We generated the alternate ANN models using five input neurons, two hidden neurons, and three output neurons. In consonance with prior studies (e.g., Talwar et al., 2020f; Hew et al., 2019; Leong et al., 2020), we confirmed the predictive accuracy of the ANN models by assessing the root mean square errors (RMSE). The models had a high accuracy of prediction in the case of postponement, with the mean RMSE of training data equal to 0.2004 and that of the validation data being equal to 0.2149 . The predictive accuracy of the models was also high in the case of opposition and rejection, with the mean RMSE of training data equal to 0.1748 and 0.1970, respectively, and that of the validation data equal to 0.1794 and 0.2097 . 


\begin{tabular}{|l|l|l|l|l|l|l|l|l|l|l|l|}
\hline & $\boldsymbol{\alpha}$ & AVE & CR & UB & VB & RB & TB & IB & POST & OPP & REJ \\
\hline UB & 0.92 & 0.72 & 0.93 & $\mathbf{0 . 8 5}$ & & & & & & & \\
\hline VB & 0.85 & 0.60 & 0.86 & 0.75 & $\mathbf{0 . 7 7}$ & & & & & & \\
\hline RB & 0.90 & 0.71 & 0.92 & 0.59 & 0.57 & $\mathbf{0 . 8 4}$ & & & & & \\
\hline TB & 0.82 & 0.57 & 0.85 & 0.51 & 0.55 & 0.38 & $\mathbf{0 . 7 5}$ & & & & \\
\hline IB & 0.81 & 0.50 & 0.82 & 0.65 & 0.67 & 0.57 & 0.53 & $\mathbf{0 . 7 1}$ & & & \\
\hline POST & 0.92 & 0.68 & 0.92 & 0.52 & 0.57 & 0.41 & 0.41 & 0.60 & $\mathbf{0 . 8 2}$ & & \\
\hline OPP & 0.89 & 0.62 & 0.90 & 0.70 & 0.69 & 0.56 & 0.52 & 0.66 & 0.64 & $\mathbf{0 . 7 9}$ & \\
\hline REJ & 0.76 & 0.58 & 0.80 & 0.62 & 0.54 & 0.39 & 0.45 & 0.45 & 0.40 & 0.57 & $\mathbf{0 . 7 6}$ \\
\hline
\end{tabular}

Table 2. Validity and reliability statistics

$\alpha=$ Cronbach's alpha; $\mathrm{CR}=$ Composite reliability; $\mathrm{AVE}=$ Average variance extracted; $\mathrm{UB}=$ Usage barrier; $\mathrm{VB}=$ Value barrier; $\mathrm{RB}=$ Risk barrier; $\mathrm{TB}=$ Tradition barrier; $\mathrm{IB}=$ Image barrier; $\mathrm{POST}=$ Postponement; $\mathrm{OPP}=$ Opposition; REJ $=$ Rejection

Bold values in diagonal are the square root of AVE, and the off-diagonal values are correlations (significant at $\mathrm{p}<$ $0.05)$

\subsection{Sensitivity analysis}

Finally, we conducted a sensitivity analysis to determine the relative influence of the five barriers on the three levels of resistance/non-adoption. Toward this end, we calculated their normalized importance by expressing each value as a percentage of the maximum relative importance. As presented in the heat map in Figure 6, the influence of the five barriers on the three levels of resistance/non-adoption differed.

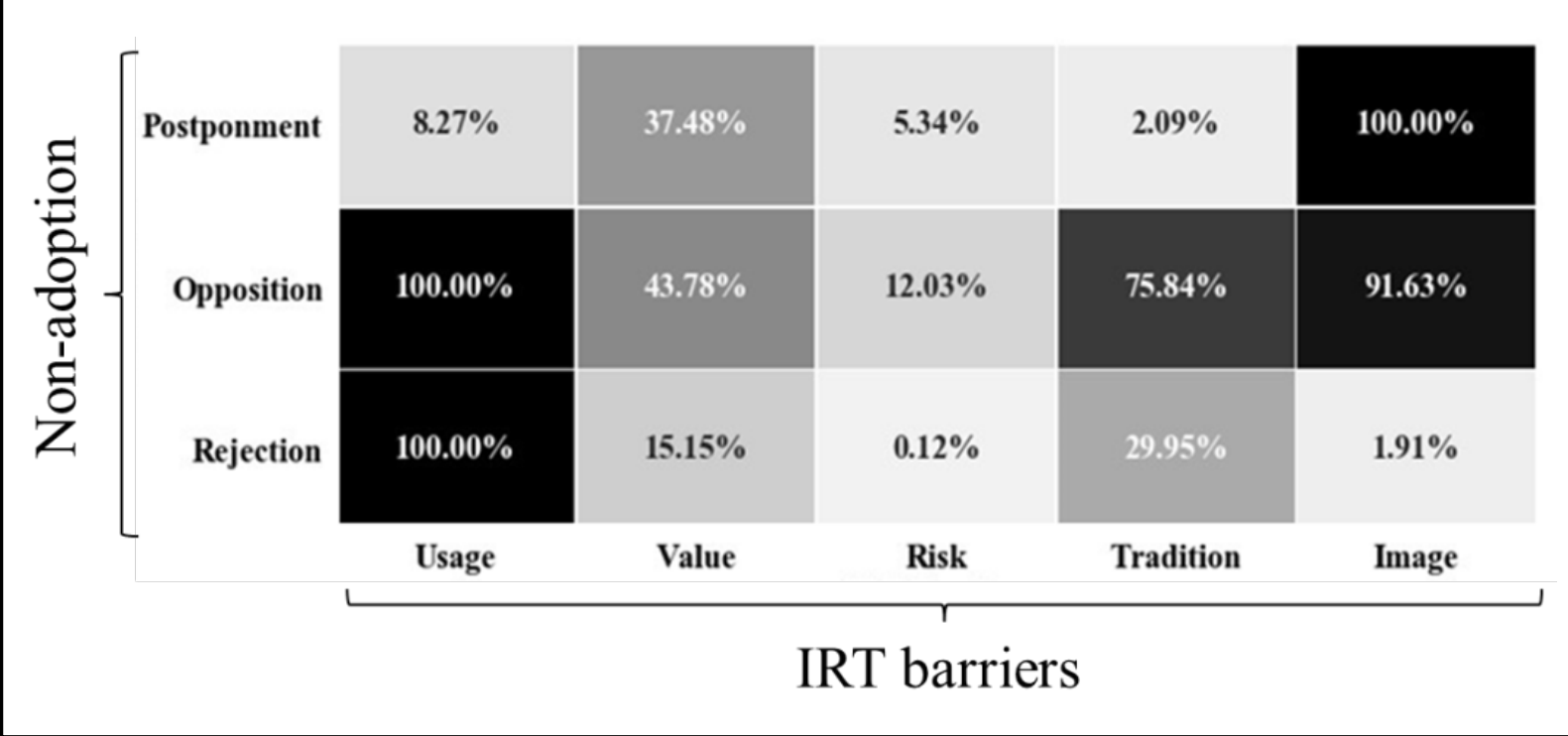

Figure 6. Heat map of the relative influence of the IRT barriers on resistance/non-adoption

\section{Discussion of findings}

Our study revealed that all five barriers influenced postponement, opposition, and rejection intentions toward m-payments during the COVID-19 pandemic. Fig. 7 presents the values, direction, and linearity/non-linearity of the relationships uncovered by our analyses. The finding related to the differences in how the classic IRT barriers influence the three levels of resistance/non-adoption is in consonance with prior studies in different contexts (Elbadrawy 
\& Aziz, 2011; Gurtner, 2014; Laukkanen et al., 2008; Laukkanen, 2016; Lian \& Yen, 2013). The differences in the effect of each individual barrier on the three levels of resistance are discussed below.

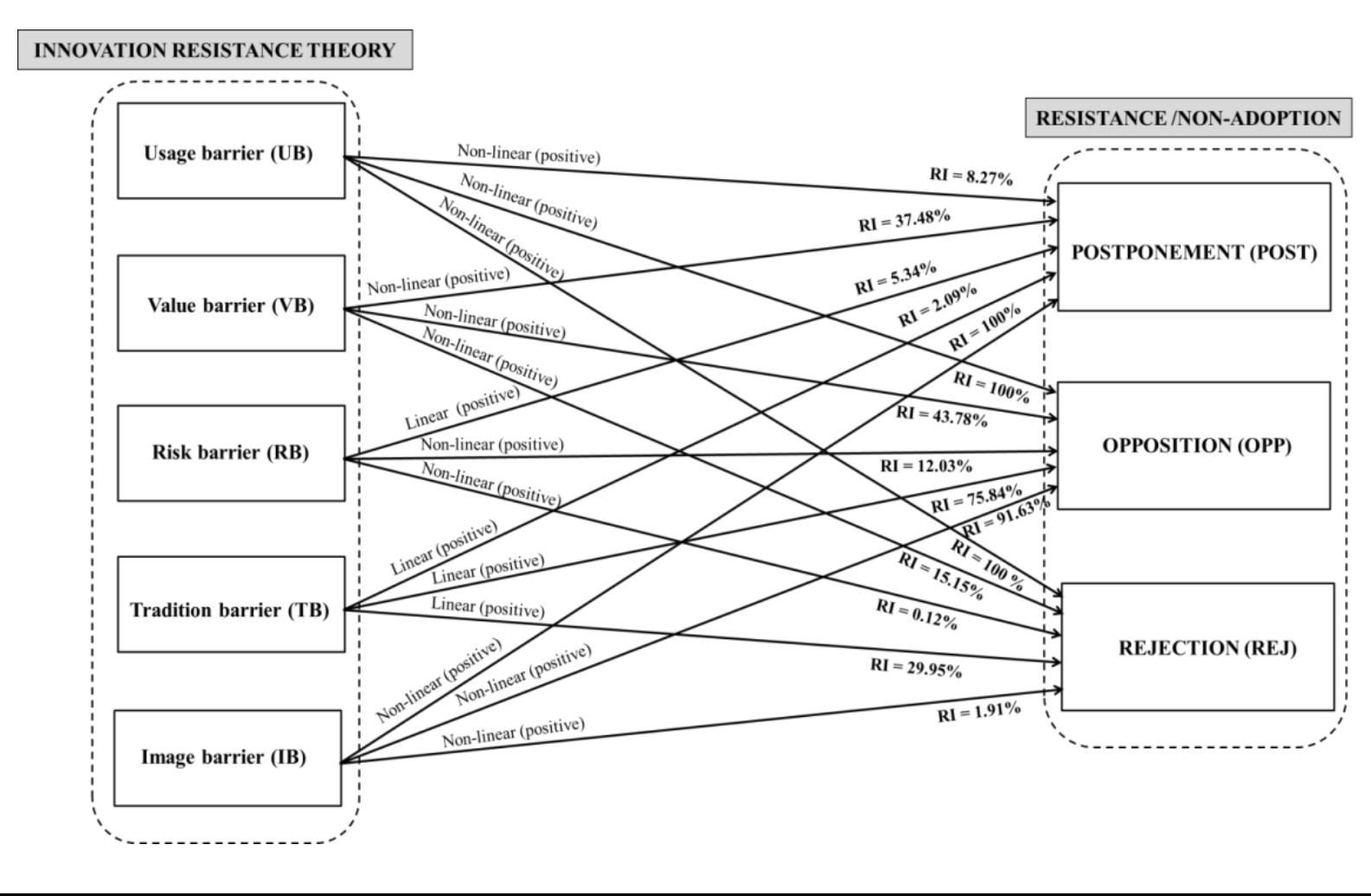

Figure 7. Results of sensitivity analysis

Usage barrier and resistance/non-adoption: Based on the values of normalized relative importance, the influence of the usage barrier was highest on opposition and rejection, followed by postponement (Figures 6 and 7). Moreover, the relationship was non-linear and positive (based on the correlation value in Table 2) for all three dependent variables. This implies that consumers develop a strong feeling of opposition and even rejection toward such services due to issues, including difficulty in handling the apps, slow interface, the tedious process of using them to send or receive payments, and the complicated information and data entry requirements. Such issues would also cause some individuals to postpone using $\mathrm{m}$ payments while they seek more information. However, the influence of the usage barrier on postponement intentions is very small, indicating that issues with handling and interface are unlikely to cause consumers to postpone using such methods for transactions.

Value barrier and resistance/non-adoption: The influence of the value barrier on opposition and postponement intentions was almost same, as seen from the values of normalized relative importance in Figures 6 and 7. Moreover, the relationship was positive and non-linear. This finding implies that if consumers feel that m-payment methods do not offer any additional advantages for sending and receiving payments compared with other methods, such as cash, card, and internet banking, they are likely to postpone or even oppose the use of these methods. Similarly, limits on the amount of money that can be transferred in a day, no enhancement in the ability to control financial matters, and limited promotional benefits, such 
as a discount or cashback, influence the intentions to postpone or oppose the use of these methods for sending and receiving payments during a pandemic. Finally, the influence of the value barrier on rejection intentions was quite small, indicating that the lack of value offered is unlikely to lead consumers to completely reject m-payment methods for sending and receiving payments during the pandemic. This relationship was also positive and non-linear (Table 2 and Figure 7).

Risk barrier and resistance/non-adoption: Surprisingly, the risk barrier had the lowest relative influence of all three levels of resistance/non-adoption, as seen from the value of its normalized relative importance (Figure 6). Moreover, the relationship was positive and linear in the case of postponement and positive and non-linear in the case of opposition and rejection (Table 2 and Figure 7). These results imply that the fear of transferring money to the wrong contact, paying extra amounts, being debited multiple times, and failed transactions have a relatively low influence in causing consumers to postpone, oppose, or reject the use of these methods. Consequently, the issues related to the safety of making a mobile-based payment may not cause consumers to delay using them, actively criticize them, or try to prevent others from using them.

Tradition barrier and resistance/non-adoption: Based on the value of normalized relative importance, as presented in the heat map in Fig. 6, the tradition barrier had a maximum influence on opposition intentions, followed by some influence on rejection intentions and comparatively low influence on postponement intentions. Moreover, the relationship was positive and linear for all three levels of resistance/non-adoption (Table 2 and Figure 7), suggesting that if consumers are more comfortable with cash transactions for sending and receiving payments and prefer physically going to banks to make money transfers, they are also likely to actively attack or protest the use of m-payments and discourage others from using them. Moreover, such consumers would oppose or even reject the use of m-payment methods on the grounds that they are out of sync with the well-entrenched ways of sending and receiving payments.

Image barrier and resistance/non-adoption: Finally, the image barrier was the most important barrier for postponement intentions, followed by opposition intentions and rejection intentions, as indicated by the normalized relative importance values presented in Figure 6. Furthermore, the relationship was positive and non-linear for all three levels of resistance/nonadoption (Table 2 and Figure 7), which indicates that consumers who feel that using $\mathrm{m}$ payments for sending and receiving payments is too difficult and complicated are likely to delay the use of these methods. Similarly, if the consumers feel that m-payments have frequent instances of transaction failures and require a lot of work, such as linking a bank account and mobile number, they may delay the use of these methods. Image barrier had a similar effect on opposition intentions, indicating that non-users not only think that m-payments are not useful, but they also tell their social circle not to use these methods for sending and receiving payments. In comparison, the influence of the image barrier on rejection was quite low.

Differences among three levels of resistance/non-adoption: As anticipated, the relative influence of these five barriers on the three levels of resistance/non-adoption varied. Specifically, the image barrier was the most influential barrier in the case of postponement, while the usage barrier was the most influential barrier for opposition and rejection. The other barriers influencing postponement, in decreasing order of relative importance, were value, usage, risk, and 
tradition. In the case of opposition, the other influential barriers were, from most to least important, the image, tradition, value, and risk barriers. Finally, in the case of rejection, the other influential barriers, again in decreasing order of importance, were tradition, value, image, and risk barriers.

\section{Conclusion, implications, limitations, and future research areas}

The adoption/non-adoption of mobile-based payments during the pandemic has varied nuances that need to be understood by the academic researchers as well as the service providers. Since the COVID-19 pandemic is a temporary aberration that is expected to end with the coming of a vaccine or the success of governments in controlling its further spread, an investigation of the depth and breadth of mobile based-payment non-adoption/adoption behavior during the pandemic is important for generating consumer behavior insights from a long-term perspective. The present study thus attempted to examine the effect of barriers toward these payment methods on varying levels of resistance. The study objectives were formally stated through two research questions.

RQ1 proposed to examine the influence of usage, value, risk, tradition, and image barriers toward the use of m-payments during the pandemic to assess the impact of varying levels of resistance/non-adoption, i.e., postponement, opposition, and rejection.

RQ2 sought to confirm if there were differences between the relative influence of usage, value, risk, tradition, and image barriers toward the use of m-payments during the pandemic on the varying levels of resistance/non-adoption, i.e., postponement, opposition, and rejection.

We proposed the conceptual model to respond to these research questions on the basis of IRT (Ram \& Sheth, 1989) and analyzed data collected from 406 smartphone users who had not yet adopted m-payment methods using ANN. The results of the study indicated that all five barriers, namely, usage, value, risk, tradition, and image, impacted the varying levels of resistance/non-adoption, i.e., postponement, opposition, and rejection, to using m-payments during the pandemic. Evaluating the alternative ANN models further confirmed that the barriers differed in their relative influence on consumers' postponement, opposition, and rejection of such services. Specifically, the usage barrier was the most important barrier for opposition and rejection intentions, whereas the image barrier was the most influential barrier for postponement intentions. The other influential barriers impacting postponement were value, usage, risk, and tradition. In the case of opposition, the other influential barriers were image, tradition, value, and risk. Finally, in the case of rejection, the other influential barriers were tradition, value, image, and risk barriers. The study has several interesting implications for theory and practice.

\subsection{Theoretical implications}

The study offers four key theoretical implications. First, it contributes to an improved understanding of resistance and non-adoption. There is a conflict in the existing literature regarding whether the two are the same or different (Cornescu \& Adam, 2013; Chen et al., 2019; Patsiotis et al., 2013). This study presents the opposing view and attempts to find the sources of similarity and differences in these two conceptualizations. By doing so, the study sets the groundwork for a more nuanced debate centered on resistance versus non-adoption. 
Second, the study provides empirical evidence that enhances the knowledge of consumer behaviour toward m-payments in three ways: (a) by bringing forth the fact that resistant behaviors need as much focus as adoption behaviors to explain consumer response to these payment methods; (b) by shifting focus to a less developed but more realistic idea that consumer resistance should not be looked at in an aggregate manner alone but by dividing it into varying levels of resistance, as argued by recent studies in varying contexts (e.g., Chen et al., 2019; Park \& Koh, 2017); and (c) by underscoring the fact that classic IRT (Ram \& Sheth, 1989) barriers (usage, value, risk, tradition, and image) are useful in explaining the varying levels of resistance/non-adoption of m-payments and that, furthermore, the relative influence of each barrier on postponement, opposition, and rejection is different.

Third, the study adds a new perspective to the growing IRT literature by extending it to examine consumer behavior in an unprecedented health crisis like the COVID-19 pandemic. Since the governmental pandemic control measures, such as complete domestic shutdown and social distancing (Fang et al., 2020), have severely impacted the psychological processes of consumers, utilizing IRT to examine consumer resistance in this context can stimulate the examination of consumers' general resistant behavior during the pandemic.

Finally, this is the first empirical study to apply an artificial neural network (ANN) approach to evaluate the influence of IRT barriers on varying levels of resistance/non-adoption. ANN is a sophisticated data analysis approach that is not restricted by the various multivariate assumptions of normality, multicollinearity, homoscedasticity, and linearity. In fact, it allows the examination of both linear and non-linear relationships among the independent and dependent variables (Talwar et al., 2020f). Moreover, it presents a clear view of the relative influence of the independent variables on the dependent variables. This helps generate more robust and insightful inferences. Thus, our study contributes novelly to the methodological advancement of research on consumer resistance to m-payments.

\subsection{Practical implications}

The study offers four main implications for practice. First, it advances the idea that approaching the non-adoption of m-payments in an aggregate manner might not be helpful to service providers since their strategies are likely to be more generic. An understanding of the varying levels of consumer resistance in terms of postponement, opposition, and rejection is extremely important because it can assist service providers in developing counterstrategies and timely interventions. The finding that the influence of the five classic IRT barriers varies for different levels of resistance indicates that managers should try to understand the extent of consumer resistance and use tailor-made interventions for each class of resistors, as supported by scholars (e.g., Talwar et al., 2020a). For example, a 'call to action' type of communication or repeated follow-ups may act as a pull strategy for postponers, but not for those who actively oppose innovations.

Second, the findings of our study show that opponents and rejectors are most affected by usage barriers. Due to this, we suggest that m-payment service providers focus specifically on having a robust architecture in place for simple and fast processing of transactions as well as ensuring that their communication with potential users, both personally and through mass media platforms, emphasizes (a) ease of handling, (b) convenience, (c) a fast interface, and (d) the limited data entry requirements of their payment interface. This is in consonance with prior 
findings on the importance of communication to overcome consumer resistance (e.g., Mani \& Chouk, 2017; 2018).

Third, image barriers are the highest among the postponers of m-payment usage, which implies that managers should identify the specific reasons why individuals perceive that using $\mathrm{m}$-payments is too difficult and has frequent instances of transaction failures. This realization is important because postponers are a resistor group who are not only temporarily delaying adoption (Kuisma et al., 2007) but are also equally likely to reject the use of m-payments with time (Cornescu \& Adam, 2013). To counter this issue, service providers may develop advertisements with a storyline that underscores how m-payments benefit both society and individuals, how they make life easy, and how vulnerable populations, such as women, the elderly, and those suffering from medical issues, can have an easier and safer payment transaction interface. The backdrop of the COVID-19 pandemic can be used to further strengthen the narrative that contactless payment methods are a natural progression to protect oneself from infection and, furthermore, are a simple way to complete financial transactions. If properly executed, such efforts to reduce postponement can be rewarding for the service providers since scholars have argued that with time and information, postponement can transform into adoption (Kuisma et al., 2007).

Finally, our findings reveal that opposition is highly influenced by usage barriers as well as image $(91.63 \%)$ and tradition barriers $(75.83 \%)$. The existence of these barriers is thus likely to exacerbate opposition intentions and cause difficulties for service providers. This is particularly concerning because opposers not only aggressively challenge the innovation but also try to prevent others from accepting it (Claudy et al., 2015; Gurtner, 2014). However, opposers can still potentially adopt the innovation with time (Kuisma et al., 2007). Managers should thus look beyond lowering the usage and image barriers alone to identify the reasons why individuals perceive m-payments to be against their norms or well-entrenched practices; in turn, this knowledge will guide them in developing strategies to present m-payment methods as a healthier option for transactions, given the risk of transmission associated with currency notes (Abd Alfadil et al., 2018).

\subsection{Limitations and future research areas}

Despite its novel approach and contributions, the study presents certain limitations. First, the data was collected from a single geography using a self-report survey instrument. Thus, the study is likely to suffer from socially desirable responses, and the findings may lack generalizability. However, the study sets the foundation for future researchers to examine the varying levels of resistance among consumers and the influence of IRT barriers on these manifestations. Researchers can thus expand our model to different contexts by identifying product-specific barriers, as done by some recent studies (e.g., Talwar et al., 2020b).

Second, our study used ANN for data analysis, which is a robust method for uncovering the relative influence of antecedents on outcome variables, as posited by recent studies (e.g., Hew et al., 2019; Leong et al., 2020; Talwar et al., 2020f). However, ANN does not support hypothesis testing. Due to this, the findings of our study offer an interesting but limited perspective. Future studies can apply the more commonly used CB-SEM to test the related hypotheses and offer a more granular understanding of the dynamics.

Third, from a conceptual perspective, our model is limited to testing the influence of each barrier separately on the postponement, opposition, and rejection of $\mathrm{m}$-wallets. However, past 
studies have posited postponement and opposition as intermediate stages that may transform into rejection or adoption (Cornescu \& Adam, 2013; Kuisma et al., 2007). As such, we suggest that scholars should develop models that capture this transition and consider various mediating and moderating influences that may affect the underlying associations. Furthermore, researchers can examine our model in the post-pandemic period and compare the differences in the relative importance of barriers. If any differences are uncovered, it might be possible to identify specific barriers that are heightened in the presence of external stressors, such as a pandemic.

\section{References}

Abbas, M., Nawaz, M .S., Ahmad, J., \& Ashraf, M. (2017). The effect of innovation and consumer-related factors on consumer resistance to innovation. Cogent Business $\mathcal{E}$ Management, 4(1), 1312058.

Abd Alfadil, N. A., Mohamed, M. S., Ali, M. M., \& El Nima, E. A. I. (2018). Characterization of pathogenic bacteria isolated from Sudanese banknotes and determination of their resistance profile. International Journal of Microbiology, 2018, 1-7.

Bagozzi, R. P., \& Lee, K. H. (1999). Consumer resistance to, and acceptance of, innovations. Advances in Consumer Research, 26(12), 218-225.

Bepari, S. (2019). The number of mobile wallet users grows by 140 million per year. Retrieved October 23, 2020 from: https://www.fintechnews.org/the-number-of-mobile-walletusers-grows-by-140-million-per-year/

Chatterjee, D., \& Bolar, K. (2019). Determinants of Mobile Wallet Intentions to Use: The Mental Cost Perspective. International Journal of Human-Computer Interaction, 35(10), 859-869.

Chen, Q., Lu, Y., Gong, Y. (Yale), \& Tang, Q. (2019.). Why do users resist service organization's brand mobile apps? The force of barriers versus cross-channel synergy. International Journal of Information Management, 47, 274-282.

Claudy, M. C., Garcia, R., \& O'Driscoll, A. (2015). Consumer resistance to innovation-A behavioral reasoning perspective. Journal of the Academy of Marketing Science, 43(4), 528544 .

Claudy, M., O'Driscoll, A., Garcia, R., \& Mullen, M. (2010). Consumer resistance to green innovations: Developing a new scale and an underlying framework. In 35 ${ }^{\text {th }}$ Macromarketing Conference, Wyoming, USA.

Cornescu, V., \& Adam, C. R. (2013). The consumer resistance behavior towards innovation. Procedia Economics and Finance, 6, 457-465.

Doremalen, N. V., Morris, D. H., Holbrook, M. G., Gamble, A., Williamson, B. N., Tamin, A., Harcourt, J. L., Thornburg, N. J., Gerber, S. I., Lloyd-Smith, J. O., Wit, E. D., \& Munster, V. J. (2020). Aerosol and surface stability of SARS-CoV-2 as compared with SARS-CoV1. The New England Journal of Medicine, 382(16), 1-4.

Dickerson, M. S., \& Gentry, J. W. (1983). Characteristics of adopters and non-adopters of home computers. The Journal of Consumer Research, 10(2), 225-235.

ETGovernment. (2020). Digital payments swell as $42 \%$ Indians make multiple online payments during Covid-19 lockdown. Retrieved October 23, 2020, from 
https://government.economictimes.indiatimes.com/news/digital-payments/digitalpayments-swell-as-42-indians-make-multiple-online-payments-during-covid-19lockdown/75172943.

Elbadrawy, R., \& Aziz, R. A. (2011). Resistance to mobile banking adoption in Egypt: A cultural perspective. International Journal of Managing Information Technology, 3(4), 9-21.

Fang, Y., Nie, Y., \& Penny, M. (2020). Transmission dynamics of the COVID-19 outbreak and effectiveness of government interventions: A data-driven analysis. Journal of Medical Virology, 92(6), 645-659.

Fujiki, H. (2020). The use of noncash payment methods for regular payments and the household demand for cash: Evidence from Japan. The Japanese Economic Review, 71, 719-765.

Gao, L., \&Waechter, K. A. (2017). Examining the role of initial trust in user adoption of mobile payment services: An empirical investigation. Information Systems Frontiers, 19(3), 525548.

Ganiere, P., Chern, W., Hahn, D., \& Chiang, F. S. (2004). Consumer attitudes towards genetically modified foods in emerging markets: The impact of labeling in Taiwan. The International Food and Agribusiness Management Review, 7(3), 1-20.

Gatignon, H., \& Robertson, T. S. (1989). Technology diffusion: An empirical test of competitive effects. Journal of Marketing, 53(9), 35-49.

Gupta, A., \& Arora, N. (2017). Understanding determinants and barriers of mobile shopping adoption using behavioral reasoning theory. Journal of Retailing and Consumer Services, $36,1-7$.

Gurtner, S. (2014). Modelling consumer resistance to mobile health applications. ECIS 2014 Proceedings $-22^{\text {nd }}$ European Conference on Information Systems, Tel Aviv, Israel.

Hair, J. F., Black, W. C., Babin, B. J., \& Anderson, R. E. (2016). Multivariate Data Analysis.7th Edition. Pearson: India.

Hew, J. J., Leong, L. Y., Tan, G. W. H., Ooi, K. B., \& Lee, V. H. (2019). The age of mobile social commerce: An Artificial Neural Network analysis on its resistances. Technological Forecasting and Social Change, 144, 311-324.

Hirschheim, R., \& Newman, M. (1988). Information systems and user resistance: Theory and practice. The Computer Journal, 31(5), 398-408.

Hosseini, M. H., Delaviz, M., Derakhshide, H., \& Delaviz, M. (2016). Factors affecting consumer resistance to innovation in mobile phone industry. International Journal of Asian Social Science, 6(9), 497-509.

Jaganmohan, M. (2020). COVID-19 impact on use of digital payments in India 2020. Retrieved October 23, 2020, from https://www.statista.com/statistics/1111082/india-coronavirusimpact-on-digital-payment-usage/.

Jakhiya, M., Bishnoi, M.M., \& Purohit, H. (2020). Emergence and growth of mobile money in modern India: A study on the effect of mobile money. 2020 Advances in Science and 
Engineering Technology International Conferences (ASET), 1-10, doi: 10.1109/ASET48392.2020.9118375.

Kaur, P., Dhir, A., Singh, N., Sahu, G., \& Almotairi, M. (2020a). An innovation resistance theory perspective on mobile payment solutions. Journal of Retailing and Consumer Services, 55, 102059.

Kaur, P., Dhir, A., Bodhi, R., Singh, T., \& Almotairi, M. (2020b). Why do people use and recommend m-wallets? Journal of Retailing and Consumer Services, 56, 102091.

Khanra, S., Dhir, A., Kaur, P., \& Joseph, R. P. (2021). Factors influencing the adoption postponement of mobile payment services in the hospitality sector during a pandemic. Journal of Hospitality and Tourism Management, 46, 26-39. Doi:10.1016/j.jhtm.2020.11.004

Kleijnen, M., Lee, N., \& Wetzels, M. (2009). An exploration of consumer resistance to innovation and its antecedents. Journal of Economic Psychology, 20(3), 344-357.

Kuisma, T., Laukkanen, T., \& Hiltunen, M. (2007). Mapping the reasons for resistance to internet banking: A means-end approach. International Journal of Information Management, 27(2), 75-85.

Kumar, S., Dhir, A., Talwar, S., Chakraborty, D., \& Kaur, P. (2021). What drives brand love for natural products? The moderating role of household size. Journal of Retailing and Consumer Services, 58, 102329. Doi:10.1016/j.jretconser.2020.102329

Laukkanen, T. (2016). Consumer adoption versus rejection decisions in seemingly similar service innovations: The case of the internet and mobile banking. Journal of Business Research, 69(7), 2432-2439.

Laukkanen, P., Sinkkonen, S., \& Laukkanen, T. (2008). Consumer resistance to internet banking: Postponers, opponents and rejectors. International Journal of Bank Marketing, 26(6), 440-455.

Laukkanen, T., Sinkkonen, S., Kivijärvi, M., \& Laukkanen, P. (2007). Innovation resistance among mature consumers. Journal of Consumer Marketing, 24(7), 419-427.

Leong, L. Y., Hew, T. S., Ooi, K. B., \& Wei, J. (2020). Predicting mobile wallet resistance: A twostaged structural equation modeling-artificial neural network approach. International Journal of Information Management, 51, 102047.

Lian, J. W., \& Yen, D. C. (2013). To buy or not to buy experience goods online: Perspective of innovation adoption barriers. Computers in Human Behavior, 29(3), 665-672.

Mani, Z., \& Chouk, I. (2017). Drivers of consumers' resistance to smart products. Journal of Marketing Management, 33(1-2), 76-97.

Mani, Z., \& Chouk, I. (2018). Consumer resistance to innovation in services: Challenges and barriers in the Internet of Things ea. Journal of Product Innovation Management, 35(5), 780-807.

Mittelstaedt, R. A., Grossbart, S. L., Curtis, W. W., \& Devere, S. P. (1976). Optimal stimulation level and the adoption decision process. Journal of Consumer Research, 3(2), 84-94. 
Mohtar, S., \& Abbas, M. (2015). Consumer resistance to innovation due to perceived risk: Relationship between perceived risk and consumer resistance to innovation. Journal of Technology and Operations Management, 10(1), 1-13.

Nabih, M. I., Bloem, J. G., \& Poiesz, T. B. C. (1997). Conceptual issues in the study of innovation adoption behavior. Advances in Consumer Research. 24, 190-196.

Oh, Y. J., Park, H. S., \& Min, Y. (2019). Understanding location-based service application connectedness: Model development and cross-validation. Computers in Human Behavior, 94, 82-91.

Park, K., \& Koh, J. (2017). Exploring the relationship between perceived pace of technology change and adoption resistance to convergence products. Computers in Human Behavior, $69,142-150$.

Patsiotis, A. G., Hughes, T., \& Webber, D. J. (2013). An examination of consumers' resistance to computer-based technologies. Journal of Services Marketing, 27(4), 294-311.

Podsakoff, P. M., MacKenzie, S. B., Lee, J. Y., \& Podsakoff, N. P. (2003). Common method biases in behavioral research: A critical review of the literature and recommended remedies. Journal of Applied Psychology, 88(5), 879-903.

Poon, W. C. (2008). Users' adoption of e-banking services: The Malaysian perspective. Journal of Business and Industrial Marketing, 23(1), 59-69.

Pousttchi K., \& Schurig M. (2004). Assessment of today's Mobile Banking applications from the view of customer requirements. Proceedings of the 37th Hawaii International Conference on System Sciences, Big Island, HI, USA.

Ram, S. (1987). A model of innovation resistance. Advances in Consumer Research, 14, 208-212.

Ram, S., \& Sheth, J. N. (1989). Consumer resistance to innovations: The marketing problem and its solutions. Journal of Consumer Marketing, 6(2), 5-14.

Seth, H., Talwar, S., Bhatia, A., Saxena, A., \& Dhir, A. (2020). Consumer resistance and inertia of retail investors: Development of the resistance adoption inertia continuance (RAIC) framework. Journal of Retailing and Consumer Services, 55, 102071.

Sharma, S., Singh, G., Sharma, R., Jones, P., Kraus, S., \& Dwivedi, Y. K. (2020a). Digital health innovation: Exploring adoption of COVID-19 digital contact tracing apps. IEEE Transactions on Engineering Management, 1-17.

Sharma, S., Singh, G., \& Pratt, S. (2020b). Does Consumers' Intention to Purchase Travel Online Differ Across Generations? Empirical Evidence from Australia. Australasian Journal of Information Systems, 24, 1-31.

Silic, M., \& Ruf, C. (2018). The effects of the elaboration likelihood model on initial trust formation in financial advisory services. International Journal of Bank Marketing, 36(3), 572-590.

Simard, R., \& L'Ecuyer, P. (2011). Computing the two-sided Kolmogorov-Smirnov distribution. Journal of Statistical Software, 39(11), 1-18.

Soh, P. Y., Heng, H. B., Selvachandran, G., Anh, L. Q., Chau, H. T. M., Son, L. H., Abdel-Baset, M., Manogaran, G., Varatharajan, R. (2020). Perception, acceptance and willingness of 
older adults in Malaysia towards online shopping: A study using the UTAUT and IRT models. Journal of Ambient Intelligence and Humanized Computing. https://doi.org/10.1007/s12652-020-01718-4.

Suzuki, Y., \& Williams, L. R. (1998). Analysis of EDI Resistance Behavior. Transportation Journal, 37(4), 36-44.

Szmigin, I., \& Foxall, G. (1998). Three forms of innovation resistance: The case of retail payment methods. Technovation, 18(6-7), 459-468.

Talke, K., \& Heidenreich, S. (2014). How to overcome pro-change bias: Incorporating passive and active innovation resistance in innovation decision models. Journal of Product Innovation Management, 31(5), 894-907.

Talwar, S., Dhir, A., Kaur, P., \& Mäntymäki, M. (2020b). Barriers toward purchasing from online travel agencies. International Journal of Hospitality Management. 89, 102593.

Talwar, S., Dhir, A., Kaur, P., \& Mäntymäki, M. (2020d). Why do people purchase from online travel agencies (OTAs)? A consumption values perspective. International Journal of Hospitality Management, 88, 102534.

Talwar, S., Dhir, A., Kaur, P., Zafar, N., \& Alrasheedy, M. (2019). Why do people share fake news? Associations between the dark side of social media use and fake news sharing behavior. Journal of Retailing and Consumer Services, 51, 72-82.

Talwar, S., Dhir, A., Khalil, A., Mohan, G., Islam, A. K. M. N. (2020c). Point of adoption and beyond. Initial trust and mobile-payment continuation intention. Journal of Retailing and Consumer Services, 55, 102086.

Talwar, M., Talwar, S., Kaur, P., Islam, A. K. M. N., \& Dhir, A. (2020e). Positive and negative word of mouth (WOM) are not necessarily opposites: A reappraisal using the dual factor theory. Journal of Retailing and Consumer Services, 102396. Doi:10.1016/j.jretconser.2020.102396

Talwar, S., Talwar, M., Kaur, P., \& Dhir, A. (2020a). Consumers' resistance to digital innovations: A systematic review and framework development. Australasian Marketing Journal. https://doi.org/10.1016/j.ausmj.2020.06.014.

Talwar, M., Talwar, S., Kaur, P., \& Dhir, A. (2020f). Has financial attitude impacted the trading activity of retail investors during the COVID-19 pandemic? Journal of Retailing and Consumer Services, 58, 102341.

Thomas, Y., Vogel, G., Wunderli, W., Suter, P., Witschi, M., Koch, D., Tapparel, C., Kaiser, L., (2008). Survival of influenza virus on banknotes. Applied and Environmental Microbiology, 74(10), 3002-3007.

UNDP. (2020). COVID-19 pandemic. Retrieved October 23, 2020, from https://www.undp.org/content/undp/en/home/coronavirus.html.

WHO. (2020a). WHO coronavirus disease (COVID-19) dashboard. Retrieved October 23, 2020, from https://covid19.who.int/. 
WHO. (2020b). Coronavirus disease (COVID-19): How is it transmitted? Retrieved October 23, 2020, from https://www.who.int/news-room/q-a-detail/coronavirus-disease-covid-19how-is-it-transmitted

Woodside, A.G., \& Biemans, W. G. (2005). Modeling innovation, manufacturing, diffusion, and adoption/rejection processes. Journal of Business and Industrial Marketing, 20(7), 380393.

Xu, X., Chen, P., Wang, J., Feng, J., Zhou, H., Li, X., Zhong, W., \& Hao, P. (2020). Evolution of the novel coronavirus from the ongoing Wuhan outbreak and modeling of its spike protein for the risk of human transmission. Science China Life Sciences, 63(3), 457-460.

Yin, Z., Gong, X., Guo, P., \& Wu, T. (2019). What drives entrepreneurship in digital economy? Evidence from China. Economic Modelling, 82, 66-73

\section{Appendix: Measurement items}

\section{Usage barrier}

1. Using a mobile wallet for sending and receiving payments was difficult for me

2. Using a mobile wallet for sending and receiving payments was inconvenient for me

3. Mobile wallets often hang or work slowly when used for sending and receiving payments

4. The steps to use mobile wallets for sending and receiving payments are not clear to me.

5. Entering data (name, age, etc.) in a mobile wallet for sending and receiving payments is a complicated process.

\section{Value barrier}

1. A mobile wallet does not offer any advantage for sending and receiving payments compared with other payment methods (e.g., cash, card, internet banking)

2. Using a mobile wallet for sending and receiving payments does not increase my ability to control my financial matters by myself.

3. Mobile wallets only allow a limited amount of money to be transferred in a day when used for sending and receiving payments

4. Mobile wallets do not offer lucrative promotional benefits (discount, cashback, etc.) when used for sending and receiving payments.

\section{Risk barrier}

1. I fear that money may be transferred to the wrong contact when using a mobile wallet for sending and receiving payments.

2. I fear that I may send the wrong amount (e.g., with an extra zero) when using a mobile wallet for sending payments.

3. I fear that money may be debited multiple times from my bank account when using a mobile wallet for sending payments.

4. An incoming phone call can fail the in-process transaction on a mobile wallet even after the money is debited for sending payments.

5. If the network signal is low, mobile wallets do not process the transaction for sending and receiving payments.

\section{Tradition barrier}

1. I am more comfortable with cash transactions.

2. Mobile wallet transactions for sending and receiving payments seem complicated to me. 
3. I like going to bank branches on a weekday for money transfers.

4. Chatting with the teller in the bank boosts my confidence in money transfers.

5. I feel that mobile wallets are not in sync with the well-entrenched ways of sending and

\section{Image barrier}

1. Using a mobile wallet for sending and receiving payments requires a lot of work (linking a bank account, mobile number, Aadhar card, etc.)

2. Using a mobile wallet for sending and receiving payments causes frequent transaction failures.

3. Using a mobile wallet for sending and receiving payments is suitable only for the youth.

4. Using a mobile wallet for sending and receiving payments is too complicated to be useful.

5. I have an image that using mobile wallets for sending and receiving payments is a difficult process.

\section{Postponement}

1. I think that sending and receiving payments using a mobile wallet is easy, but I do not use it.

2. I think a mobile wallet is useful, but I am not using a mobile wallet for sending and receiving payments now.

3. I am not sure whether using a mobile wallet for sending and receiving payments is the right decision now.

4. I shall observe if people face any problem with using a mobile wallet before using it for sending and receiving payments myself.

5. I do not generally jump into using an innovation.

\section{Opposition}

1. I do not think that using a mobile wallet for sending and receiving payments is a good idea.

2. I do not think that a mobile wallet is useful for sending and receiving payments.

3. I tell my friends not to use mobile wallets for sending and receiving payments.

4. I tell my friends why it is not a good idea to use a mobile wallet for sending and receiving payments.

5. If a friend suggests that a mobile wallet is useful for sending and receiving payments, I shall oppose him/her.

\section{Rejection}

1. I think that avoiding mobile wallets for sending and receiving payments is the right decision.

2. I think that users do not get any financial benefit from sending and receiving payments using a mobile wallet.

3. I do not recommend to my friends using mobile wallets for sending and receiving payments.

4. If a friend suggests that a mobile wallet is useless for sending and receiving payments, I shall support him/her. 
Copyright: (C) 2021 authors. This is an open-access article distributed under the terms of the Creative Commons Attribution-NonCommercial 3.0 Australia License, which permits noncommercial use, distribution, and reproduction in any medium, provided the original author and AJIS are credited.

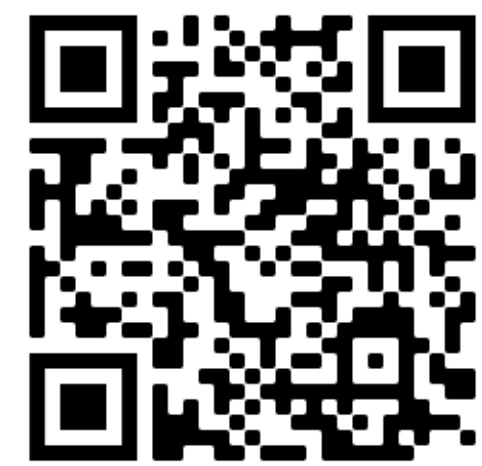

